\title{
La presencia del pensamiento narrativo en la letra de las canciones
}

\author{
The presence of narrative \\ thinking in song lyrics
}

\author{
Óscar Julián Cuesta (Colombia) \\ Fundación Universitaria Los Libertadores \\ oscarcuesta@colombia.com
}

\author{
Alberto Gómez (Colombia) \\ Fundación Universitaria Los Libertadores \\ alberto.gomezm@gmail.com
}

\begin{abstract}
Resumen
El presente artículo presenta los resultados de una investigación que buscó identificar la presencia del pensamiento narrativo en las letras de las canciones. Para ello, realizó un análisis de la letra de tres canciones de diferentes géneros de la música latinoamericana: Jaime Molina, de Rafael Escalona (vallenato), Plantación adentro, de Rubén Blades (salsa) y Matador, de Los Fabulosos Cadillacs (ska), el cual utilizó una matriz de análisis construida con categorías
\end{abstract}

\section{Abstract}

This article presents the results of an investigation aimed at identifying the presence of narrative thinking in song lyrics. For this, an analysis of the lyrics of three songs from different genres of Latin American music was carried out: Jaime Molina, by Rafael Escalona (vallenato) Plantación Adentro, by Ruben Blades (salsa) and Matador, by Los Fabulosos Cadillacs (ska) The analysis used an analytical framework constructed by categories of narrative thinking. Finally, the article
FECHA DE RECEPCIÓN:

FECHA DE REVISIÓN:

APROBACIÓN:
17 de abril de 2013

15 de julio de 2013

17 de octubre de 2013
Para Citar este artículo / to Cite this ARTicle Cuesta, O. \& Gómez, A. (2013). La presencia del pensamiento narrativo en la letra de las canciones. Poliantea, (IX), 17, pp. 153-170. 
del pensamiento narrativo. Finalmente, el artículo plantea la importancia de estimular el pensar narrativo como posibilidad para configurar sujetos con conciencia histórica.

Palabras clave: música, pensamiento narrativo, lectura de contexto. discusses the importance of stimulating the narrative thinking as a possibility to configure subjects with historical consciousness.

Keywords: music, narrative thinking, reading context. 


\section{La presencia del pensamiento narrativo en la letra de las canciones}

\section{The presence of narrative thinking in song lyrics}

\author{
Óscar Julián Cuesta (Colombia) \\ Comunicador social y magíster en Educación
}

\author{
Alberto Gómez (Colombia) \\ Profesional en Estudios Literarios y es- \\ pecialista en Pedagogía. \\ Maestrante en Educación
}

\section{Introducción}

A primera vista la relación entre comunicación y música puede ser obvia: surgida del seno social, empieza por ser una reacción íntima hecha discurso que pasa a ser colectiva por necesidad. Igual que no hay lectura sin lectores, no hay música sin público. La apuesta musical implica poner en común una experiencia de vida a un público heterogéneo, el cual se vuelve colectivo en torno al mensaje que, o bien puede ser solo sonido y sentimiento, $o$ ser sonido, sentimiento y relato.

La música es, a la vez, producto y constructo que posibilita cultura, apoyada en los músicos, que ofician de transmisores. Con las voces y arte ha alegrado las veladas de los grupos humanos, e implica en sus letras una memoria que, aunque en la mayoría de casos resulta pasajera, apenas limitada a unas cuantas generaciones, ha demostrado que cuando es alcanzada por el éxito comercial, es capaz de convertirse hasta en símbolo patrio. 
La música es un código social, elemento integrador y productor de colectivos. Emerge como consecuencia de la pasión del músico y compositor por el mundo en que vive. Curiosamente notamos que las canciones son aceptadas o no, lo que podría significar que, como síntesis de las formas de ver el mundo, las producciones musicales fungen como transmisores de patrones de comportamiento que fijan los universos perceptivos de los públicos.

La música "penetra" y llena de sentido la experiencia humana de que procede. La música contagia, emociona, empalaga; está relacionada con cada uno de nuestros momentos, los enuncia de hecho, los representa y, por supuesto, los transforma. Pero no es solo experiencia individual, ya que las relaciones de sentido que instauramos en torno a los temas define una forma de percibir la realidad propia de los colectivos. Es decir, la música nos acerca no solo a una experiencia íntima, profunda e individual, sino que es en esencia una manifestación colectiva en torno a la vida, que está presente de dos modos: uno netamente sensitivo e intuitivo, experimentada como sonido, y el otro (la letra), cognitivo relacional y afectivo, producto de la experiencia de vida, manifiesto como enseñanza o recuerdo.

Podrían hacerse diversos análisis comunicativos de las cadencias rítmicas, de los instrumentos, de los lenguajes no verbales, de los músicos que interpretan o de los contextos. Nuestra intención en este caso es acercarnos a la íntima relación de la música con la comunicación desde la exploración de sus contenidos verbales.

Siguiendo a Guillén (2004), no desconocemos el placer experimentado por la conjugación de parámetros musicales - sonidos rítmicos- y lingüísticos - la letraque poseen las canciones; de hecho, hacer este ejercicio parte de encontrar el gozo por la música.

La idea es poner a consideración de los lectores la presencia del pensamiento narrativo en el mensaje escrito de tres canciones. Es pertinente decir que el ejercicio presentado no es un análisis de narrativa musical (Maus, 1990) ni un análisis tan solo musical (Nagore, 2004), sino que hace un ejercicio de lectura de la letra de tres canciones a partir de los fundamentos del pensamiento narrativo (Brunner, 1999). 


\section{Sobre el pensamiento narrativo}

Empecemos por establecer qué es el pensamiento narrativo. El psicólogo constructivista Jerome Bruner en su obra Realidad mental y mundos posibles (1999), planteó que los seres humanos se acercan a la realidad a partir de dos modalidades de pensamiento: el paradigmático y el narrativo.

De acuerdo con Bruner, el primero se caracteriza por la visión lógico-científica imperante en nuestras sociedades. Bajo su amparo se busca explicar a través de categorías y conceptos la realidad y nuestras experiencias de ella de una forma racional, sintética, en la que resulta importante la enunciación de causalidades sobre cualquier aspecto que interese. Cuando enunciamos la realidad bajo esta modalidad de pensamiento se diría que nuestra preocupación es la de indagar las causas generales de lo que nos inquieta. Para ello, se hace uso de un lenguaje que se constituye, enunciando su punto de vista desde la experiencia de lo verificable u observable. El pensamiento lógico o paradigmático, persigue lo universal en tanto rechaza lo particular, ${ }^{1}$ por ello su expresión excelsa es la teoría.

Por su parte, el pensamiento narrativo se ocupa de intenciones y acciones humanas, y trata de situar la experiencia en algún tiempo y espacio, lo que si bien no lo aleja por completo de la noción de universalidad, sí limita dicha noción, circunscribiéndola a situaciones concretas en las que se concentra. Este modo de pensar se organiza a partir del relato de lo ordinario, lo cotidiano, la experiencia de alguien, sus acciones, su historia. Por ello resulta más común asociar esta forma de pensamiento con nuestra cotidianidad, siendo que nuestra necesidad de referencialidad (quién soy y dónde estoy) se extiende normalmente con nuestras redes afectivas.

En el pensamiento narrativo se identifican una meta y unos sujetos que piensan, deciden, actúan a favor o en contra de ella. Y si bien en el caso de la lectura clínica se identifica la presencia del pensamiento narrativo en la voz del paciente que relata sus sueños, en la vida cotidiana este pensamiento se multiplica

\footnotetext{
Para ver una crítica a las presunciones universales de las ciencias occidentales, ver Zemelman (1996).
} 
en las voces de todos cuando intentamos apresar el tiempo que se escapa para dar cuenta de nuestra vida y lo que ha sido de ella, a otros. En el caso de la música el bombardeo de historias se multiplica por las voces y por los públicos que encuentran en las letras la enunciación de sus relatos.

Para Bruner (1999), en todo relato o narración existe una intención previa, manifiesta en su trama y estructura. Esta trama es la que permite saber la manera y el orden en que las cosas sucedieron. La estructura del relato es el modo como se articulan el conflicto, los personajes y la conciencia de estos, cimentado todo en el básico comienzo, nudo y desenlace.

Según este autor, en el pensamiento narrativo es fundamental la capacidad de subjuntivizar la realidad, es decir, de encontrar en la narración lo permitido, lo verosímil, la posibilidad de que lo narrado se corresponda con un mundo posible. ${ }^{2}$ Una narración es buena o aceptada

2 En los relatos podemos encontrar hipótesis narrativas que permiten varias interpretaciones, esto es, construyen varios mundos posibles. El científico, por el contrario, busca que sus planteamientos solo tengan una posible interpretación, una sola perspectiva del mundo. más fácilmente si el lector o el oyente encuentran en ella, desde sus marcos referenciales, la capacidad de que sea posible, es decir, de que pueda explicarse desde sus conocimientos, creencias y deseos.

Así, al escuchar un relato, el lector u oyente lo juzga descabellado o creíble de acuerdo con los referentes que ha interiorizado en su mente y que dictan la perspectiva de lectura del mundo. Pero este relato alcanza significado gracias a la potencia que le imprime su estructura general.

Escribe Bruner (1999: 46):

La gran narración consiste, inevitablemente, en abordar conflictos humanos que resulten "accesibles" a los lectores. Pero, a la vez, los conflictos deben presentarse con la suficiente subjuntividad para que puedan ser reescritos por el lector, a fin de permitir el lenguaje de su imaginación.

En pocas palabras, el pensamiento narrativo permite al sujeto A relatar la realidad a partir de la experiencia, $\mathrm{y}$ al sujeto $\mathrm{B}$ recrear ese relato y juzgarlo posible o imposible, tomar posición sobre los personajes y opinar sobre las acciones bajo su particular marco referencial, o si se quiere, bajo unos cánones del mundo de significados. 
En otro texto, Bruner (1991) explica que estos cánones se esquematizan en la cultura, más precisamente, en los cánones de cada cultura. Así, el "mundo objetivo" de un niño canadiense es diferente al de una niña pakistaní musulmana. De hecho, las formas de explicar el mundo que tenemos desde niños están determinadas por lo que este autor llama psicología popular, que aprendemos escuchando los relatos de los mayores y de nuestros pares. De esta manera, la cultura es la que regula las versiones que tenemos de la realidad.

Una de las trascendencias del pensamiento narrativo es que implica una "predisposición a organizar la experiencia de forma narrativa" (Bruner, 1991: 58). En otras palabras, las versiones del mundo, de la realidad, se organizan en narraciones que, si bien en líneas generales se caracterizan por tener personajes, escenarios, conflictos y acciones que se encadenan en sucesos en un tiempo (tradicional inicio, nudo, desenlace), procuran cumplir con los sistemas culturales donde se originan, con las formas particulares de leer el mundo y negociar-renegociar los significados en cada comunidad.

Para ir finalizando esta primera parte, hemos de decir que estas dos modalidades de pensamiento no se excluyen; al contrario, son complementarias: un psicólogo para explicar el comportamiento de su paciente no solo recurre al libro que teoriza sobre sus causas, también recuerda que un colega suyo le contó de un paciente similar y de la terapia que siguió con él $y$, por su parte, un paciente recurre, más que a la explicación lógica de aquello que le atormenta, al relato de lo acontecido en su vida o en sus sueños.

Lo cierto es que, en últimas, uno y otro pensamiento nos permiten crear la realidad. El problema para las ciencias y aun para la educación quizá radica en que se privilegia el pensamiento científico o paradigmático y los currículos de la educación se enfilan preponderantemente a su desarrollo. Pero el conocimiento es complejo y depende de una realidad dinámica que muchas veces necesita más del pensamiento narrativo que del paradigmático, en razón a que aquel es situado, localizado e histórico, en tanto que este crea un mundo invariable, basado en universales, sin tiempo ni espacio, lo que lo hace estar desbordado por la incertidumbre propia de la complejidad.

Es importante aclarar que el análisis de los textos seleccionados 
se limitó a los límites del pensamiento narrativo expuestos anteriormente, $y$ no tiene en cuenta las nociones de narrativa musical, abordados por autores como Maus (1990), Newcomb (1987), Micznik (2001), sino se acerca más a la propuesta de Paz, Jacquier y Shifres (2013), quienes plantean una posible narrativa de la música basada en la cualidad dinámica de la experiencia, lo cual se articula con lo propuesto en este artículo.

\section{Metodología}

Para identificar la presencia del pensamiento narrativo en las letras de las canciones, se realizó un análisis de las letras de las siguientes tres piezas: Jaime Molina, de Rafael Escalona (vallenato); Plantación adentro, de Rubén Blades (salsa) y Matador, de Los Fabulosos Cadillacs (ska). La selección de las canciones se estipuló mediante muestreo a conveniencia, determinado por el gusto de los investigadores y se procuró buscar ejemplos de diferentes géneros musicales. No obstante, las canciones seleccionadas requerían cumplir con estos criterios: sus letras debían estar en español, presentar personajes, relaciones temporales, escenarios y algún tipo de conflicto que permitiera ver algún entramado narrativo.

Para el análisis se diseñó una matriz que especificaba estas categorías presentes en el pensamiento narrativo: realidad, subjuntividad, relato y cultura.

\section{Resultados y discusión}

A continuación se exponen las letras de las canciones y sus respectivos análisis.

La primera, Jaime Molina, es una canción clásica del folclor colombiano. Su género es el vallenato y su autor es un referente obligado para los vallenatólogos: el maestro Rafael Escalona. Y antes de observar el pensamiento narrativo, recordemos la letra:

(A dos amigos que se amaron con el alma, ¡ay, hombe!)

Recuerdo que Jaime Molina, cuando estaba borracho, ponía esta condición: que si yo moría primero él me hacía un retrato,

o si él se moría primero, le sacaba un son; que si yo moría primero él me hacía un retrato,

o si él se moría primero, le sacaba un son.

Ahora prefiero esta condición: que él me hiciera el retrato y no sacarle el son. 
Ahora prefiero esta condición: que él me hiciera el retrato $y$ no sacarle el son.

Famosas fueron sus parrandas que a ningún amigo dejaba dormir.

Cuando estaba bebiendo

siempre me insultaba

con frases de cariño

que él sabía decir.

Cuando estaba bebiendo

siempre me insultaba

con frases de cariño

que él sabía decir.

Después en las piernas

se me sentaba,

me contaba un chiste y

se ponía a reír.

Después en las piernas

se me sentaba,

me contaba un chiste y

se ponía a reír.

La cosa comenzó muy niño:

Jaime Molina me enseñó a beber, a dondequiera estaba él conmigo $y$ dondequiera estaba yo con él, a dondequiera estaba él conmigo y dondequiera estaba yo con él.

Ahora me duele que él se haya ido, yo quedé sin Jaime y él sin Rafael. Ahora me duele que él se haya ido, yo quedé sin Jaime y él sin Rafael.

Nacido en Patillal, Cesar, el 27 de mayo de 1927, Rafael Escalona desde muy temprana edad empezó a retratar sus vivencias en canciones que fácilmente se convirtieron en parte del repertorio musical de los colombianos.
Suyas son La casa en el aire, El testamento, La vieja Sara, La brasilera, La Maye, María Tere, La patillalera, El pobre Migue, López el Pollo o La creciente, canciones que indudablemente nos hacen pensar en un hombre enamoradizo que se servía de la música no tanto para consolarse de sus penas, como para enamorar. Un narrador por excelencia que con su música logró redefinir el espacio de la provincia y llevarla a distintos puntos de la tierra, lo que le valió convertirse en una especie de símbolo de la cultura nacional.

Sin embargo esta canción, titulada originalmente Elegía a Jaime Molina, es precisamente un ejemplo de la excepción a la regla. En ella narra las vivencias del compositor junto a su amigo, el pintor $\mathrm{y}$ caricaturista Jaime Molina, quien falleciera en agosto de 1978. Aquí, claramente, el pensamiento narrativo se hace presente como el organizador de la experiencia: donde el pasado es reconstruido en el presente (verbo "recuerdo" de la primera estrofa) siguiendo los elementos básicos del relato: sujetos (Jaime y Rafael), acciones a favor de una meta o conflicto (si uno muere primero, el otro hace un retrato, o viceversa, un son) y grado de conciencia de los 
personajes sobre el conflicto ("ahora prefiero está condición").

Aunque no se puede establecer un inicio, nudo y desenlace de manera lineal, sí se puede observar una estructura narrativa que articula sucesos aleatorios que, fácilmente, el lector (u oyente en este caso) puede recuperar y recrear.

Siguiendo a Bruner (1999), la canción cumple con la característica de la subjuntividad, es decir, relata algo posible, lo que si bien nos invita a pensar en la necesidad de verosimilitud, cualidad de que debe estar dotado todo relato para preciarse de ser coherente y ser aceptado, también nos señala su tendencia a la transformación. De hecho, al escuchar la canción, el oyente siente cierta simpatía por el relato, no tanto porque con él reconstruya exclusivamente la historia de Jaime y Rafael, sino porque en ella es latente la posibilidad de recordar al amigo perdido desde un contexto que resulta similar a aquel en el que se inician los hombres de la costa caribe colombiana.

Ya lo decíamos, una de las funciones más importante de la música es que por su misma condición, posibilita convertir un tema en un código que lleva a la memoria situaciones que guardan algún tipo de relación con el contenido, pero, sobre todo, que enmarcan la experiencia de vida en un contexto ritual acorde con las expectativas de los oyentes. En este caso, la narración expuesta en la canción es lo que Bruner (1991) llama la autobiografía del yo, pues es un relato del sujeto y sus vivencias desde el contexto cultural propio al autor. Autor y narrador que como vemos, en este caso, se confunden en uno solo, permitiendo a su vez confundirse en la interpretación con el intérprete, ocasionalmente, el mismo oyente.

En cuanto al sistema de códigos que opera, es evidente que para comprender las dimensiones del dolor de esta pérdida es necesario conocer los ritos de iniciación de la cultura vallenata, una cultura caracterizada por la alegría, el machismo, la expresión sentimental libre y permisiva que lleva a que al son de la música y con el acompañamiento del licor los hombres "sean más hombres" y, ante todo, más amigos. De hecho la canción valora el amor de amigos, llevándolo a un plano ideal, en el que es claro el tipo de relación y sus límites.

Por otro lado, se observa que el autor acata las negociaciones 
culturales de creación de significados, como lo demuestra el uso, por ejemplo, de la expresión "parranda", que hace referencia a la reunión de música y baile alrededor de un grupo de intérpretes con instrumentos. En este segmento del relato la palabra fiesta o sus sinónimos sonaría forzada o descontextualizada, pero "parranda", en cambio, nos concentra en el espacio singular de la vida vallenata. Podríamos especular que si Escalona hubiera sido de otro país hablaría de farra, juerga o jarana, pero en cambio, "parranda", después de la Elegía a Jaime Molina, se reafirma como un código implícito en las formas de enunciar el festejo entre nuestros compatriotas de la costa caribe y de todo aquel que identifique la región con el territorio y el ser nacional.

La segunda canción, Plantación adentro, contrariamente al tema del maestro Escalona, emplea una voz mucho más cercana a la de los relatos literarios, la tercera persona del singular. La famosa voz omnisciente.

Por tanto, en este tema no encontraremos la enunciación como tal de un pasado propio idealizado por la subjetividad del autor y menos a un narrador que se confunde con el autor de la historia. No, en
Plantación adentro el pensamiento narrativo cumple otro propósito discursivo. Su fábula se organiza en torno a un pasado común a los pueblos expropiados, lo que la sitúa en el terreno de la denuncia. La historia, con la narración del asesinato de un trabajador de las fincas cafetaleras, desmitifica la versión oficial del progreso donde todo se alcanza con el esfuerzo conjunto y valeroso sin distingos de raza.

Su autor, el cantante panameño Rubén Blades, conspicuo exponente de la salsa latina, es además uno de los pocos autores e intérpretes de este género que se ha destacado por su singular compromiso político y social, siendo que no solo con esta canción (véase Pedro Navaja, América, etc.), convirtió los temas sociales en parte de la rumba cotidiana. Esta es la letra:

Sombras son la gente.

A la la la la la la la (bis). Plantación adentro, camará, es donde se sabe la verdad, es donde se aprende la verdad.

Dentro del follaje $y$ de la espesura, donde todo viaje lleva la amargura, es donde se sabe, camará, es donde se aprende la verdad. 
Camilo Manrique falleció por golpes que daba el mayoral y fue sepultado sin llorar, ija!, una cruz de palo y nada más.

Camilo Manrique falleció plantación adentro, camará, plantación adentro, camará, sombra son la gente y nada más.

Se murió el indio Camilo por palos que daba el mayoral.

Y el médico de turno dijo así: "Muerte por causa natural".

Claro, si después de una tunda e'palo, que te mueras, es normal.

Tierra, selva, sol y viento, indio y palo e' mayoral.

¡Eh!, Camilo Manrique falleció $y$ lo enterraron sin llorar.

$Y$ en su triste monumento, una cruz de palo y nada más.

Recoge el café y coge pa'lla', si no te pega el mayoral. Selva verde selva traga, selva nunca dice na'.

Plantación adentro, camará sombra son la gente y nada más.

Las primeras estrofas introducen la narración, sirven de preludio y presentan dos elementos centrales, el escenario y el conflicto: la plantación (más adelante nos dice que es de café) y el problema de la verdad.
En seguida, comienza el relato: Camilo Manrique fue asesinado por su jefe, pero la versión oficial dice que fue por causas naturales. La narración, además, nos presenta otros elementos fundamentales para entender la trama: Camilo era indígena, nadie lloró su muerte y su sepulcro lo avisa una cruz de palo.

Para la interpretación y el análisis quedarán las connotaciones de estas referencias: la conquista y la colonización, que permitieron la acumulación de las riquezas de Europa, se basó en la racialización (de allí nace la categoría indio como menos humano que el blanco europeo) que justificó la explotación violenta e implantaron a la fuerza otra cosmovisión y prácticas culturales (simbolizada en la cruz). ${ }^{3}$

El hecho de no llorar su muerte puede indicar la soledad de Camilo, pero más allá de esto, se puede revelar que hay una naturalización de la práctica y que los sujetos que la padecen ya la asumen de manera resignada.

3 Para ver más sobre la colonialidad del poder y la importancia de la clasificación de las razas como elemento constitutivo de la modernidad y el capitalismo, ver Quijano (2000). 
Aunque Blades especifica un año en la introducción de la canción (1745), podemos decir que puede ser una historia vigente, de principios de siglo XX o de este año, pues las prácticas de monocultivo en grandes latifundios siguen presentes en el continente, así como el asesinato de obreros de estas plantaciones: por ejemplo, varios paramilitares en Colombia han declarado que su función era eliminar los líderes para evitar las huelgas en los cultivos de banano en Urabá. ${ }^{4}$ Lo mismo podemos suponer con el lugar de la plantación: al ser esta café, puede ser un país de la zona tropical de América. ¿Por qué no lo especifica el autor? Porque las prácticas latifundistas y las condiciones de los obreros no cambian mucho entre estos países.

En últimas, la canción indica que dentro de plantación se sabe la verdad: fue asesinado a palos por su jefe. De la plantación para afuera se afirma que su muerte se debió a causas naturales. Esto, evidentemente, tiene que ver con las dinámicas de poder y de narración de la historia: ${ }^{5}$

4 Ver documental Impunity, de Hollman Morris.

5 Sobre este tema, se puede ver el análisis que hace Gentile (2009) de las madres a mayor control, mayor capacidad de agenciar la memoria, de allí que la historia contada y repetida en los colegios sea la oficial. Esto se puede observar fácilmente en los medios de comunicación: quién habla, por cuánto tiempo, en qué horario, etc. La canción da cuenta de la otra historia, de la versión que no tiene micrófono, de los sujetos sin voz.

Lo anterior es muy importante, pues las narraciones de las canciones se convierten en alternativas para contar la otra historia y construir la memoria colectiva. De esta manera, la música se convierte en plataforma que pone en común (comunica) lo no expuesto o distorsionado por el relato oficial, y lo hace mediante otro lenguaje, cercano a todos, no uno docto, de élite, como la historiografía académica. De esta manera, las canciones y sus narraciones se convierten en fuentes de información que permiten a los sujetos ampliar su conciencia: darse y dar cuenta del mundo ${ }^{6}$ en un

de los desaparecidos en la dictadura en Argentina.

6 Estas ideas siguen a Zemelman (2006) y su propuesta de la conciencia histórica, en la cual es vital que el sujeto potencialice diferentes lenguajes para acercarse a la realidad; en ese caso, proponemos las canciones vistas como narraciones. 
momento histórico concreto (su contexto).

Por otra parte, esta canción hace explícitas las intenciones políticas y sociales de Rubén Blades, autor que, entre otras cosas, es un buen ejemplo de pensamiento narrativo, pues sus canciones se caracterizan por relatar crónicas de personajes y problemas cotidianos (tal vez el ejemplo más universal de su repertorio es $P e$ dro Navaja). En ese orden de ideas, podemos decir que las canciones pueden exponer la colocación éticopolítica del autor (narrador) frente a su lectura de la realidad.

Para finalizar, la tercera canción sobre la que queremos hablar, no se refiere ni a una experiencia personal, ni a una historia ficticia con visos de verosimilitud. Matador es una canción que, quizá muy en la línea de desacralización de la historia oficial a que se hizo referencia anteriormente con el tema de Rubén Blades, se encarga de mitificar una figura en el imaginario colectivo, haciendo, de paso, famosa a la banda de rock y ska Los Fabulosos Cadillacs en el continente. La letra es la siguiente:

Te están buscando, Matador. Me dicen el Matador, nací en barracas; si hablamos de matar, mis palabras matan, no hace mucho tiempo que cayó el León Santillán $y$ ahora sé que en cualquier momento me la van a dar. Me dicen el Matador, me están buscando; en una fría pensión los estoy esperando, agazapado en lo más oscuro de mi habitación; fusil en mano, espero mi final.

Matador, Matador, ¿dónde estás, Matador? Matador, Matador: no te vayas, Matador. Matador, ;oh, yeah! Matador, Matador. Vientos de libertad, sangre combativa, en los bolsillos del pueblo la vieja herida, de pronto el día se me hace de noche. Murmullos, corridas, el golpe en la puerta, llegó la fuerza policial.

¡Papapao!... Ma... Matador: mira, hermano, en qué terminaste por pelear por un mundo mejor. ¿Que suenan?, son balas, me alcanzan, me atrapan; resiste, Victor Jara no calla.

Matador, Matador, Matador, te están buscando. Matador, Matador, Matador, te están matando. Matador, ;oh, yeah! Matador, Matador. Me dicen el Matador de los cien barrios porteños. No tengo por qué tener miedo, 
mis palabras son balas, balas de paz, balas de justicia; soy la voz de los que hicieron callar sin razón por el solo hecho de pensar distinto, ¡ay, Dios!

Santa María de los Buenos Aires, si todo estuviera mejor...

Matador, Matador, si todo estuviera mejor...

Matador, Matador, ¿a dónde vas, matador? Matador, Matador, Matador.

La canción se convirtió en un éxito juvenil a principios de los noventa y se puede decir que catapultó el éxito en Latinoamérica y Europa de Los Fabulosos Cadillacs, muy conocidos ya en aquella época en su contexto cultural.

Se puede decir que esta canción, al igual que la de Blades o Escalona, se enmarca en un espacio-tiempo correspondiente a dos universos de expectativas. Por una parte, el de la cultura de la que procede la historia, que le sirve como referente de un constructo discursivo que se enmarca en la ficción, y por otro el del público que crea, al que se dirige o que intenta construir.

El pensamiento narrativo en este caso es puesto al servicio de un fin ciertamente ideológico que parte de la enunciación de un hecho registrado en la historia, con fuertes implicaciones políticas, como fue la muerte del cantante y líder socialista Víctor Jara a manos de la dictadura chilena en 1973. Sin embargo, la canción no enuncia la historia real de Víctor Jara, solo lo nombra, lo convierte en referente, más bien en clave para entender que en realidad habla de un espíritu de lucha, de un sentimiento.

Es importante decir que en este caso el éxito de la canción riñe entre lo llamativo del video promocional (guiño evidente de la industria cultural) que ganó premios en $\mathrm{Mu}-$ sic Television (MTV), y lo irónico de la muerte del personaje que encarna los valores e ideales libertarios del socialismo.

En la letra resuenan con evidencia los ecos de las dictaduras latinoamericanas, las tiranías y las demagogias, como ecos intertextuales (no hace mucho tiempo que cayó el León Santillán) de una historia donde la barbarie ha sido ejercida en otras ocasiones por las fuerzas que se encuentran en el poder (véanse otras letras del grupo como Quinto Centenario, Yo no me sentaría en tu mesa, Mal bicho o Manuel Santillán el León), pero, también, y especialmente, resuena el espíritu combativo de la juventud con un tema que, 
esta vez desde una primera persona totalmente ficticia y haciendo gala del estilo directo, se convierte en el héroe combativo que está dispuesto a transformar la historia. Lo curioso es que aquí la figura del matador (que paradójicamente recuerda la fiesta taurina) termina evocando al chivo expiatorio que es asesinado por las fuerzas que se encuentran en el poder, lo que lo lleva a ser un símbolo mesiánico para los jóvenes que han disfrutado de la canción.

Así, encontramos que si bien el objetivo de la canción al principio, parece ser la de concentrar la atención en el personaje y en su forma de morir ("agazapado en lo más oscuro de mi habitación, fusil en mano, espero mi final"), lo cual no la alejaría de lo meramente anecdótico y convencional, a poco notamos que el acento en realidad se concentra en el legado que deja ese héroe ("soy la voz de los que hicieron callar sin razón, por el solo hecho de pensar distinto, ¡ay, Dios!).

Esto demuestra que el pensamiento narrativo se nos ofrece no solo como una posibilidad de contar lo sucedido o de lamentarse, no solo es una posibilidad de enunciar el dolor o el fracaso, la imposibilidad de la vida o sus certezas, sino que es ante todo una plataforma moral que ofrece la posibilidad de recrear el universo significativo de los seres humanos, volcándonos en personajes que, existentes o no, pero siempre presentes en la mente de los oyentes, ubican puntos de referencia que sirven para mirar el mundo con los ojos de la utopía.

\section{Conclusiones}

Este trabajo pudo determinar un vínculo entre el pensamiento narrativo y las letras en las canciones analizadas. Es importante decir que estas dejan que el oyente recupere un mundo posible, porque las letras plantean referentes culturales que hacen entender e imaginar lo narrado. Igualmente, no está de más reconocer que esa conjugación musical y lingüística permite, de algún modo, placer en el que escucha (Guillén, 2004).

A manera de cierre, quisiéramos proponer que esta dinámica expuesta del pensamiento narrativo y su vinculación en la música sea usada de manera deliberada en la formación de sujetos, en especial, en la configuración de la conciencia histórica.

Por un lado, el pensamiento narrativo coloca al sujeto en una realidad narrada; desde ese punto de 
vista, permite ser fuente de análisis de las construcciones sociales, sobre todo de los significados socialmente construidos y culturalmente heredados.

Por otro lado, hacerlo con canciones deja ver cómo estas son narraciones que expresan una idea de mundo, una lectura de realidad, en un momento dado, en una coyuntura, con lo cual da cuenta de aspectos de la realidad que, muchas veces, no son expresados por la historiografía oficial o por el periodismo mismo.

En ese orden de ideas, es allí donde el pensamiento narrativo, aunado con el texto musicalizado, permite formar sujetos con conciencia histórica, pues a través de las canciones se pueden conocer realidades que los sujetos ignoraban o, que viéndolas, no habían problematizado. Recordemos que este ejercicio es fundamental si se quiere construir futuro: solo sujetos conscientes de su presente como expresión condensada de su pasado y futuro pueden determinar el sentido de sus horizontes.

\section{Referencias}

Bruner, J. (1999). Realidad mental y mundos posibles. Barcelona: Gedisa.

Gentile, B. (2009). Pensar desde la emergencia. México: Cerezo Editores.

Guillén, L. (2004). Relación texto/ música: procesos perceptivos en la canción popular. Actas del V Congreso Latinoamericano de la Asociación Internacional para el Estudio de la Música Popular. Recuperado de http://www.iaspmal.net/wp-content/uploads/2011/12/LorenaGuillen.pdf

Maus, F. (1990). Music as narrative. Indiana Theory Review, 12, 1-34.

Micznik, V. (2001). Music and narrative revisited: degrees of narrativity in Beethoven and ahler. Journal of the Royal Musical Association, 126, 193-249.

Nagore, M. (2004). Análisis musical, entre el formalismo y la hermenéutica. Músicas al Sur, 1. Recuperado de http://www.eumus.edu.uy/ revista/nrol/nagore.html

Newcomb, A. (1987). Schuman and late eighteenth-century narrative 
strategies. 19th Century music, colonialidad del saber: eurocentrisXI(2), 164-174. mo y ciencias sociales. Perspectivas

Paz Jacquier, M. y Shifres, F. (2013). Fundamentos psicológicos y educacionales de la teoría de la narrativa musical. Recuperado de http:// www.saccom.org.ar/actas_eccom/ vol1-1_contenido/jacquier_y_shifres.pdf

Latinoamérica. Buenos Aires: Consejo Latinoamericano de Ciencias Sociales.

Zemelman, H. (1996). Problemas antropológicos y utópicos del conocimiento. México: Colmex.

Zemelman, H. (2006). El conociQuijano, A. (2000). Colonialidad miento como desafío posible. Méxidel poder, eurocentrismo y Américo: Instituto Pensamiento y Cultura ca Latina. En Lander, E. (comp.). La en América Latina. 